(2) Open Access Full Text Article

\title{
Comparison of dexmedetomidine and sufentanil as adjuvants to local anesthetic for epidural labor analgesia: a randomized controlled trial
}

This article was published in the following Dove Medical Press journal: Drug Design, Development and Therapy

\author{
Tao Zhang' \\ Yulong Yu' \\ Wang Zhang ${ }^{2, *}$ \\ Jin $\mathrm{Zhu}^{3, *}$ \\ 'Department of Anesthesiology, \\ Taizhou Hospital of Zhejiang Province, \\ Wenzhou Medical University, Linhai \\ 317000, People's Republic of China; \\ ${ }^{2}$ Department of Anesthesiology, \\ Affiliated Women's and Children's \\ Hospital of Jiaxing University, Jiaxing \\ 3 I 4000, People's Republic of China; \\ ${ }^{3}$ Department of Surgical Oncology, \\ Taizhou Municipal Hospital, Taizhou \\ 3/8000, People's Republic of China \\ *These authors contributed equally \\ to this work
}

Background: The epidural dexmedetomidine combined with ropivacaine has been successfully used for labor analgesia. We compared the effects of dexmedetomidine and sufentanil as adjuvants to local anesthetic for epidural labor analgesia.

Methods: Eighty nulliparous women were enrolled in the double-blind study and randomly divided into two groups. Group D received $0.5 \mu \mathrm{g} / \mathrm{mL}$ dexmedetomidine with $0.1 \%$ ropivacaine for epidural labor analgesia, and group $\mathrm{S}$ (control group) received $0.5 \mu \mathrm{g} / \mathrm{mL}$ sufentanil with $0.1 \%$ ropivacaine for labor analgesia. Hemodynamic parameters were monitored. Pain was assessed using a visual analog scale. The onset of epidural analgesia, duration of stages of labor, Ramsay Sedation Scale, blood loss, neonatal Apgar scores, umbilical artery blood pH and adverse effects, such as respiratory depression, nausea, vomiting, pruritus, and bradycardia, were recorded.

Results: Compared with the control group, visual analog scale values after cervical dilation $>3 \mathrm{~cm}$ were lower in group $\mathrm{D}(P<0.05)$ and first-stage labor duration was shorter in group D (378.5 \pm 52.6 vs 406.5 $\pm 58.2, P<0.05$ ). Ramsay Sedation Scale values were higher in group D compared to the control group $(2.8 \pm 0.6$ vs $2.4 \pm 0.5, P<0.05)$. No significant differences in side effects were observed between the groups.

Conclusion: Dexmedetomidine is superior to sufentanil in analgesic effect and duration in first-stage labor during epidural analgesia when combined with $0.1 \%$ ropivacaine (www.chictr. org.cn, registration ChiCTR-OPC-16008548).

Keywords: dexmedetomidine, sufentanil, epidural, analgesia, labor

\section{Introduction}

As an $\alpha_{2}$-adrenoceptor agonist, dexmedetomidine possesses anxiolytic, sedative, and analgesic properties without causing respiratory depression. ${ }^{1-3}$ Dexmedetomidine combined with ropivacaine has been successfully used for epidural labor analgesia, with fewer side effects. ${ }^{4,5}$ However, epidural local anesthetics combined with opioids are often accompanied by adverse effects, such as pruritus, nausea, and vomiting. The present study was designed to compare the effects of dexmedetomidine and sufentanil as adjuvants to local anesthetic for epidural labor analgesia.

\section{Methods}

This study was conducted in accordance with the Declaration of Helsinki and approved by the ethical committee of Jiaxing Women and Children's Hospital (Chairman Professor L Xia) on April 16, 2016. Written informed consent was signed by the parturients. From August 2016 to December 2016, 80 nulliparous women with American 
Society of Anesthesiologists grade I-II, aged 20-35 years, weight $55-85 \mathrm{~kg}$, and gestation $\geq 37$ weeks were enrolled in this prospective, double-blind study. Patients with a history of severe cardiopulmonary disease, bradycardia, cervical dilatation $>3 \mathrm{~cm}$, contraindications to epidural analgesia, and undergoing cesarean section or labor induction were excluded from this study. Parturients were randomly divided into the control group (group $\mathrm{S}, \mathrm{n}=40$ ) and the dexmedetomidine group (group D, $\mathrm{n}=40$ ) using a computer-generated random-number table.

After entering the delivery room, parturients' vital signs, such as blood pressure, heart rate, and $\mathrm{SpO}_{2}$, were monitored every 5 minutes, and fetal heart rate was also monitored using a Doppler fetal heart monitor. Venous access was established. Epidural analgesia was carried out when cervical dilatation was about $2 \mathrm{~cm}$. Parturients were positioned in the left lateral decubitus position, and epidural puncture was performed at the estimated level of $\mathrm{L}_{2-3}$ interspace by an 18-gauge epidural needle using loss of resistance to air. An epidural catheter was inserted 3-4 cm cephaladly into the epidural space. After a negative aspiration test for blood and cerebrospinal fluid, a test dose of $3 \mathrm{~mL} \mathrm{1 \%}$ lidocaine was administered. Subsequently, parturients received $10 \mathrm{~mL} 0.5 \mu \mathrm{g} / \mathrm{mL}$ dexmedetomidine or $0.5 \mu \mathrm{g} / \mathrm{mL}$ sufentanil combined with $0.1 \%$ ropivacaine as loading dose, and this mixed solution was infused continuously by a patient-controlled-analgesia pump (Jiangsu Aipeng Medical Devices, China) at a rate of $6 \mathrm{~mL} / \mathrm{h}$. The women were instructed to use the pump for a bolus dose. A rescue bolus of $6 \mathrm{~mL}$ (lockout 20 minutes) was administered by the pump when visual analog scale (VAS) score was $\geq 5$ ( $0=$ no pain, $10=$ maximum pain). Local-anesthetic solutions for epidural labor analgesia were prepared by another anesthetist, and investigators were blind to these solutions. Cervical dilatation progress was assessed by skilled midwives at intervals of 2 hours during the latent phase and every hour during the active phase.

\section{Outcome measures and data collection}

Blood pressure, heart rate, and $\mathrm{SpO}_{2}$ were monitored and recorded. Pain was evaluated with VAS. Onset of epidural analgesia, total analgesic consumption, duration of stages of labor, Ramsay Sedation Scale (RSS), blood loss, neonatal Apgar scores, and umbilical-artery blood gas were also noted. Onset of analgesia was defined as time from epidural administration to VAS $<3$, and duration of the first stage of labor was defined as time from epidural administration to $10 \mathrm{~cm}$ cervical dilatation. Blood loss was estimated by measuring the weight of medical gauze (1 kg approximately $1,000 \mathrm{~mL}$ ).
Side effects, ie, hypotension, pruritus, sedation, nausea/ vomiting, shivering, respiratory depression (hypoxemia), and maternal bradycardia, were also recorded and managed. The adverse effects were defined as: respiratory depression $\mathrm{SpO}_{2}<90 \%$ when inhaling air; hypotension - systolic bloodpressure reduction $>20 \%$ from baseline (before analgesia); maternal bradycardia - heart-rate reduction $>20 \%$ from baseline (before analgesia); and fetal bradycardia - fetal heart rate $<120$ beats per minute.

Level of sedation was evaluated using the RSS (1, patient anxious, agitated, or restless; 2 , patient cooperative, oriented, tranquil, and alert; 3, patient responds to commands; 4, asleep, but with brisk response to light glabellar tap or loud auditory stimulus; 5, asleep, sluggish response to light glabellar tap or loud auditory stimulus; 6 , asleep, no response). ${ }^{6} \mathrm{RSS}$ values were recorded every 60 minutes during labor. Excessive sedation was defined as RSS value $>4$.

\section{Statistical analysis}

As the primary outcome was the duration of the first stage and the secondary outcome the effects of analgesia, 36 samples were needed in each group at an $\alpha$-error of 0.05 and power of 0.80 according to our pilot data. Analysis was performed with SPSS 17.0. Numerical variables are presented as mean \pm SD. Categorical data are presented as numbers and percentages. Means were analyzed by Mann-Whitney $U$ test and categorical data analyzed by $\chi^{2} . P<0.05$ was considered significant.

\section{Results}

Eighty parturients were enrolled in this study (Figure 1). Ten women (four in group D and six in group S) were withdrawn from the study, as they had prolonged duration of first-stage labor $(>12-16 \mathrm{hrs})$ and required cesarean section. There were no significant differences in age, weight, height, or gestational weeks between the groups $(P>0.05$, Table 1$)$.

VAS values were lower in group $D$ than group $S$ when cervical dilation was $>3 \mathrm{~cm}$ (Figure 2). There were significant differences in VAS values after cervical dilation $>3 \mathrm{~cm}$ between the group $\mathrm{D}$ and group $\mathrm{S}$, but no significant differences within $3 \mathrm{~cm}$ of cervical dilation. Moreover, total analgesic consumption was reduced in group D over group $\mathrm{S},(71.5 \pm 12.2$ vs $78.1 \pm 10.5, P<0.05)$. Duration of the first stage of labor was shorter in group $\mathrm{D}$ than group $\mathrm{S}$ (378.5 \pm 52.6 vs $406.5 \pm 58.2, P<0.05)$. RSS values in both groups were $1-3$, with significant differences between the groups ( $2.8 \pm 0.6$ vs $2.4 \pm 0.5, P<0.05)$, but no excessive sedation was observed. The incidence of hypotension, shivering, nausea, vomiting, hypoxemia, and bradycardia was similar in both groups. No pruritus or motor block was observed in 


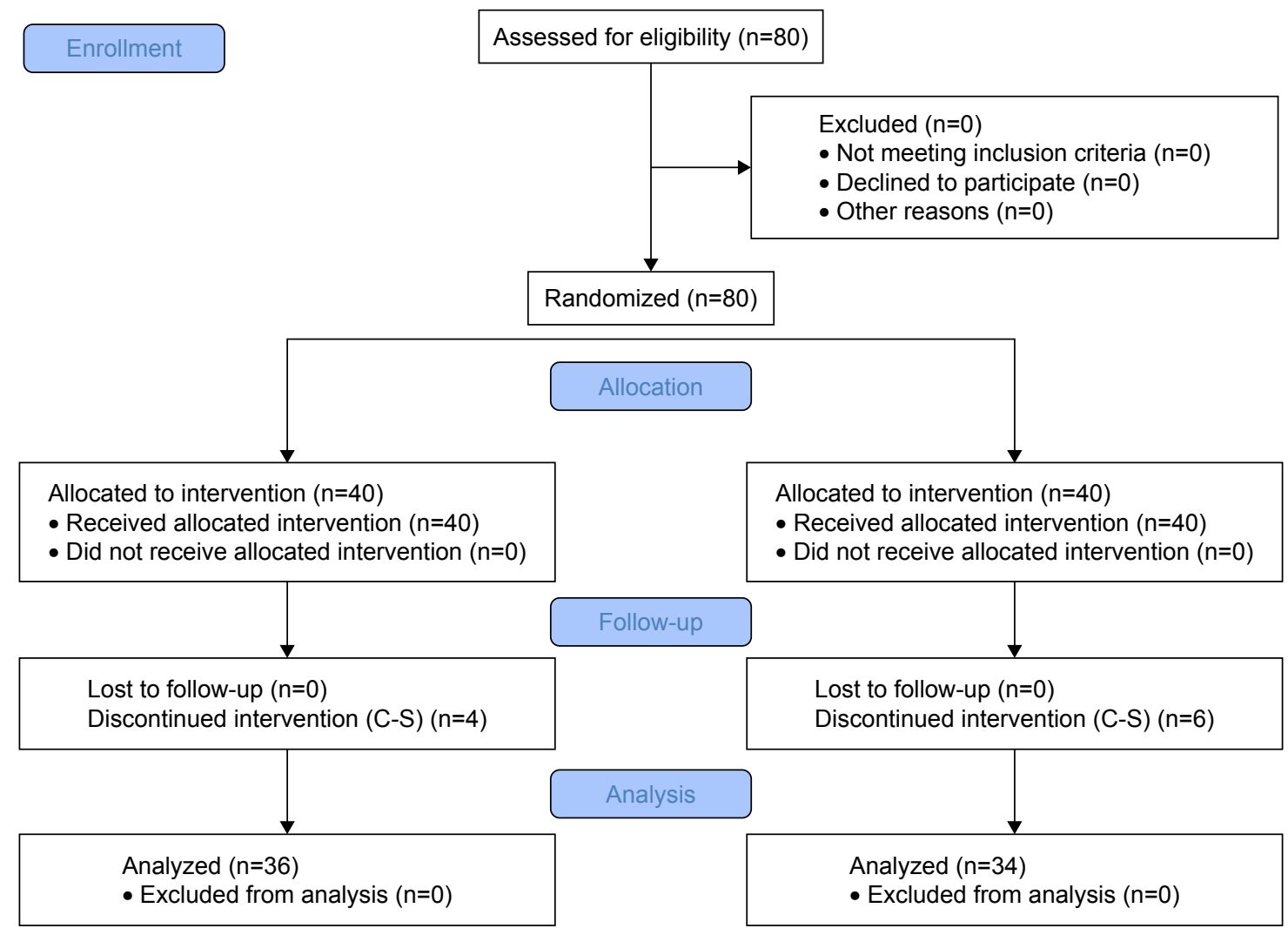

Figure I Flow diagram of study.

Abbreviation: C-S, Cesarean section.

group D, and there were no significant differences in side effects between the groups (Table 2).

\section{Discussion}

The ideal epidural analgesia should provide parturients with satisfactory analgesia without side effects for the mother or newborn, such as motor block, nausea, vomiting, pruritus, and fetal distress. In our study, we found that the analgesic effect of epidural dexmedetomidine was superior to sufentanil and duration of first-stage labor shortened during epidural labor analgesia when administered with $0.1 \%$ ropivacaine, with fewer side effects.

Table I Data of parturients

\begin{tabular}{l|l|l|l}
\hline & Group D (n=36) & Group S (n=34) & P-value \\
\hline Age (years) & $27.3 \pm 3.6$ & $26.7 \pm 3.1$ & 0.460 \\
Weight (kg) & $70.8 \pm 4.7$ & $69.5 \pm 5.4$ & 0.289 \\
Height (cm) & $159.3 \pm 2.9$ & $160.4 \pm 3.2$ & 0.225 \\
Gestational age (weeks) & $39.8 \pm 1.2$ & $40.1 \pm 1.3$ & 0.323 \\
Onset of analgesia (minutes) & $14.4 \pm 3.4$ & $13.9 \pm 2.6$ & 0.542 \\
Duration of first stage (minutes) & $378.5 \pm 52.6$ & $406.5 \pm 58.2$ & $0.042 *$ \\
Duration of second stage (minutes) & $38.6 \pm 5.4$ & $40.3 \pm 6.7$ & 0.251 \\
Blood loss (mL) & $192.7 \pm 13.8$ & $198.3 \pm 14.5$ & 0.108 \\
Mode of delivery (vaginal/cesarean) & $36 / 4$ & $34 / 6$ & 0.653 \\
I-minute Apgar score & $8.7 \pm 0.7$ & $8.9 \pm 0.6$ & 0.181 \\
5-minute Apgar score & $9.6 \pm 0.5$ & $9.7 \pm 0.7$ & 0.496 \\
Umbilical artery pH & $7.22 \pm 0.06$ & $7.23 \pm 0.07$ & 0.504 \\
Umbilical artery PaO (mmHg) & $28.8 \pm 2.5$ & $29.7 \pm 3.3$ & 0.488 \\
Ramsay Sedation Scale & $2.8 \pm 0.6$ & $2.4 \pm 0.5$ & $0.002 *$ \\
Total analgesics (mL) & $71.5 \pm 12.2$ & $78.1 \pm 10.5$ & $0.02 I^{*}$ \\
\hline
\end{tabular}

Notes: $* P<0.05$ compared with group $S$. Data presented as mean \pm SD or numbers. Group D received $0.5 \mu g / \mathrm{mL}$ dexmedetomidine with $0.1 \%$ ropivacaine for epidural labor analgesia, and group $\mathrm{S}$ (control group) received $0.5 \mu \mathrm{g} / \mathrm{mL}$ sufentanil with $0.1 \%$ ropivacaine for labor analgesia. 


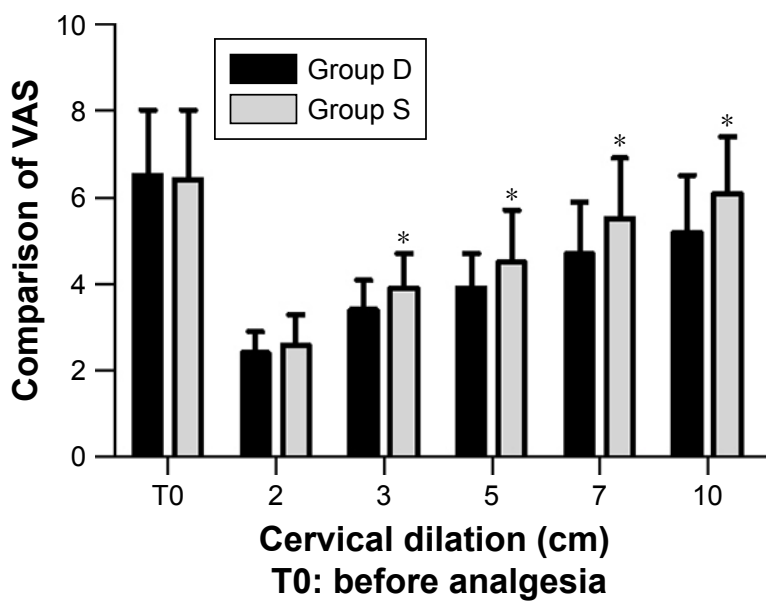

Figure 2 Comparison of visual analog scale (VAS) values at different cervical dilatations.

Notes: Group D received $0.5 \mu \mathrm{g} / \mathrm{mL}$ dexmedetomidine with $0.1 \%$ ropivacaine for epidural labor analgesia, and group $S$ (control group) received $0.5 \mu \mathrm{g} / \mathrm{mL}$ sufentanil with $0.1 \%$ ropivacaine for labor analgesia. $P<0.05$.

Ropivacaine combined with sufentanil has been used widely for epidural labor analgesia. ${ }^{7-9}$ In our study, we found that VAS values after cervical dilation $>3 \mathrm{~cm}$ were significantly lower in group $\mathrm{D}$ than group $\mathrm{S}$, and total analgesic consumption was reduced in group $\mathrm{D}$. This indicated that adding dexmedetomidine to ropivacaine for labor analgesia provided better analgesic effect than sufentanil combined with ropivacaine. Dexmedetomidine possesses sedative and analgesic properties by activating $\alpha_{2}$ receptors in the spinal cord. ${ }^{10}$ Previous studies have reported that dexmedetomidine is a better adjuvant compared to fentanyl when added to ropivacaine in terms of providing prolonged analgesic effect and reducing total consumption of analgesia. ${ }^{11,12}$ These findings are in concordance with our results in this study. We also found that duration of first-stage labor was shortened when dexmedetomidine combined with $0.1 \%$ ropivacaine was used for labor analgesia. An in vitro study proved that dexmedetomidine has the potential to enhance the frequency of uterine contractions. ${ }^{13}$ As an $\alpha_{2}$-adrenoceptor agonist, dexmedetomidine can bring

Table 2 Side effects of epidural analgesia

\begin{tabular}{l|l|l|l}
\hline & $\begin{array}{l}\text { Group D } \\
(\mathbf{n}=\mathbf{3 6})\end{array}$ & $\begin{array}{l}\text { Group S } \\
(\mathbf{n}=\mathbf{3 4 )}\end{array}$ & P-value \\
\hline Hypotension & 0 & 0 & $\mathrm{I}$ \\
Pruritus & 0 & $\mathrm{I}(2.9 \%)$ & $0.13 \mathrm{I}$ \\
Nausea and vomiting & $\mathrm{I}(2.7 \%)$ & $3(8.8 \%)$ & 0.122 \\
Maternal bradycardia & 0 & 0 & $\mathrm{I}$ \\
Fetal bradycardia & $3(8.3 \%)$ & $2(5.8 \%)$ & 0.506 \\
Respiratory depression & 0 & 0 & $\mathrm{I}$ \\
Shivering & $2(5.5 \%)$ & $3(8.8 \%)$ & $0.37 \mathrm{I}$ \\
Excessive sedation & 0 & 0 & $\mathrm{I}$ \\
\hline
\end{tabular}

Notes: Data were presented as $\mathrm{n}(\%)$. Group D received $0.5 \mu \mathrm{g} / \mathrm{mL}$ dexmedetomidine with $0.1 \%$ ropivacaine for epidural labor analgesia, and group $S$ (control group) received $0.5 \mu \mathrm{g} / \mathrm{mL}$ sufentanil with $0.1 \%$ ropivacaine for labor analgesia. about contractions of uterus smooth muscles and fasten the duration of the first stage of labor. There was no significant difference with regard to $\mathrm{SpO}_{2}$ and motor block during labor. $\mathrm{SpO}_{2}$ values were $>90 \%$ in group $\mathrm{D}$, suggesting that epidural dexmedetomidine did not result in respiratory depression. RSS values were 1-3 in both groups during labor. There was a significant difference in RSS between the groups, but no excessive sedation was observed in this study. We found RSS values increased obviously in the dexmedetomidine group because dexmedetomidine produced sedative and analgesic effects by acting on $\alpha_{2}$-adrenergic receptors. Many studies have shown that RSS values with addition of dexmedetomidine to local anesthetic are greater compared to addition of fentanyl, ${ }^{11,12,14}$ and these findings are in good agreement with our results. Opioids are well known to cause side effects such as, pruritus, nausea, vomiting, and respiratory depression. Compared with opioids, dexmedetomidine did not cause pruritus and had fewer complications of nausea and vomiting during analgesia. ${ }^{15}$ Dexmedetomidine can be used safely for epidural labor analgesia.

\section{Limitations}

Dexmedetomidine is not licensed for epidural use by the US Food and Drug Administration. The effects of dexmedetomidine on mother and fetus need further study with larger-sample trials. ${ }^{16}$ In summary, dexmedetomidine is superior to sufentanil in terms of improved analgesic effect and short duration of the first stage of labor during epidural labor analgesia when administered with $0.1 \%$ ropivacaine.

\section{Data sharing}

The authors will share participant data, such as blood pressure, heart rate, and pain scores. No other study-related documents will be available. The data will be accessible 6 months after publication from http://www.sohu.com.

\section{Acknowledgments}

This work was supported by the Jiaxing Science and Technology Bureau Fund (2017AY3305071). We thank our colleagues for their help in this study.

\section{Author contributions}

All authors contributed to data analysis, drafting or revising the article, gave final approval of the version to be published, and agree to be accountable for all aspects of the work.

\section{Disclosure}

The authors report no conflicts of interest in this work. 


\section{References}

1. Nie Y, Liu Y, Luo Q, Huang S. Effect of dexmedetomidine combined with sufentanil for post-caesarean section intravenous analgesia: a randomised, placebo-controlled study. Eur J Anaesthesiol. 2014;31(4): 197-203. doi:10.1097/EJA.0000000000000011

2. Hall JE, Uhrich TD, Barney JA, Arain SR, Ebert TJ. Sedative, anesthetic, and analgesic properties of small-dose dexmedetomidine infusions. Anesth Analog. 2000;90(3):699-705.

3. Yousef AA, Salem HA, Moustafa MZ. Effect of mini-dose epidural dexmedetomidine in elective cesarean section using combined spinalepidural anesthesia: a randomized double-blinded controlled study. J Anesth. 2015;29(5):708-714. doi:10.1007/s00540-015-2027-7

4. Wangping Z, Ming R. Optimal dose of epidural dexmedetomidine added to ropivacaine for epidural labor analgesia: a pilot study. Evid Based Complement Alternat Med. 2017;2017:4. doi:10.1155/ 2017/7924148

5. Zhao Y, Xin Y, Liu Y, Yi X, Liu Y. Effect of epidural dexmedetomidine combined with ropivacaine in labor analgesia: a randomized doubleblinded controlled study. Clin J Pain. 2017;33(4):319-324. doi:10.1097/ AJP.0000000000000411

6. Ramsay MA, Savege TM, Simpson BR, Goodwin R. Controlled sedation with alphaxalone-alphadolone. Br Med J. 1974;2(5920):656-659.

7. Beilin Y, Halpern S. Ropivacaine versus bupivacaine for epidural labor analgesia. Anesth Analog. 2010;111:482-487. doi:10.1213/ANE. 0b013e3181dd869b

8. Boulier V, Gomis P, Lautner C, Visseaux H, Palot M, Malinovsky JM. Minimum local analgesic concentrations of ropivacaine and levobupivacaine with sufentanil for epidural analgesia in labor. Int $J$ Obstetric Anesth. 2009;18(3):226-230. doi:10.1016/j.ijoa.2009.02.002
9. Benhamou D, Ghosh C, Mercier FJ. A randomized sequential allocation study to determine the minimum effective analgesic concentration of levobupivacaine and ropivacaine in patients receiving epidural analgesia for labor. Anesthesiology. 2003;99(6):1383-1386.

10. Al-Mustafa MM, Badran IZ, Abu Ali HM, Al-Barazangi BA, Massad IM, Al-Ghanem SM. Intravenous dexmedetomidine prolongs bupivacaine spinal analgesia. Middle East J Anesthesiol. 2009;20(2):225-231.

11. Bajwa SJ, Arora V, Kaur J, Singh A, Parmar SS. Comparative evaluation of dexmedetomidine and fentanyl for epidural analgesia in lower limb orthopedic surgeries. Saudi J Anaesth. 2011;5(4):365-370. doi:10.4103/ 1658-354X.87264

12. Kiran S, Jinjil K, Tandon U, Kar S. Evaluation of dexmedetomidine and fentanyl as additives to ropivacaine for epidural anesthesia and postoperative analgesia. J Anaesthesiol Clin Pharmacol. 2018;34(1):41-45. doi:10.4103/joacp.JOACP_205_16

13. Sia AT, Kwek K, Yeo GS. The in vitro effects of clonidine and dexmedetomidine on human myometrium. Int J Obstetric Anesth. 2005;14(2): 104-107. doi:10.1016/j.ijoa.2004.11.004

14. Zhang X, Wang D, Shi M, Luo Y. Efficacy and safety of dexmedetomidine as an adjuvant in epidural analgesia and anesthesia: a systematic review and meta-analysis of randomized controlled trials. Clin Drug Investig. 2017;37(4):343-354. doi:10.1007/s40261-016-0477-9

15. Grewal A. Dexmedetomidine: GA. New avenues. J Anaesthesiol Clin Pharmacol. 2011;27:297-302. doi:10.4103/0970-9185.83670

16. Konakci S, Adanir T, Yilmaz G, Rezanko T. The efficacy and neurotoxicity of dexmedetomidine administered via the epidural route. Eur J Anesthesiol. 2008;25(5):403-409. doi:10.1017/S0265021507003079

\section{Publish your work in this journal}

Drug Design, Development and Therapy is an international, peerreviewed open-access journal that spans the spectrum of drug design and development through to clinical applications. Clinical outcomes, patient safety, and programs for the development and effective, safe, and sustained use of medicines are the features of the journal, which

\section{Dovepress}

has also been accepted for indexing on PubMed Central. The manuscript management system is completely online and includes a very quick and fair peer-review system, which is all easy to use. Visit http://www.dovepress.com/testimonials.php to read real quotes from published authors.

Submit your manuscript here: http://www.dovepress.com/drug-design-development-and-therapy-journal 